Кузьмич Наталья Павловна

кандидат экономических наук,

доцент кафедры геодезии и землеустройства

Дальневосточного государственного

аграрного университета

Фролов Олег Романович

магистрант Дальневосточного государственного аграрного университета

\section{ТЕРРИТОРИАЛЬНОЕ ПЛАНИРОВАНИЕ В СИСТЕМЕ ГОСУДАРСТВЕННОГО ПЛАНИРОВАНИЯ ИСПОЛЬЗОВАНИЯ И ОХРАНЫ ЗЕМЕЛЬ}

\section{Аннотация:}

В статье рассматривается территориальное планирование, при котором создается определенный порядок, обеспечивающий организацию управления как городскими территориями, так и сельскими.

Ключевые слова:

государственное планирование, градостроительная деятельность, земельно-имущественный комплекс, землепользование, использование и охрана земель, территориальное планирование.

\section{Kuzmich Natalia Pavlovna}

\author{
PhD in Economics, \\ Assistant Professor, \\ Geodesy and Land Management Department
} Far East State Agrarian University

Frolov Oleg Romanovich

Applicant for a Master's degree, Far East State Agrarian University

\section{SPATIAL PLANNING IN THE SYSTEM OF STATE PLANNING OF LAND USE AND PROTECTION}

Summary

This article deals with spatial planning that creates a certain order providing management organization both with urban and rural areas.

Keywords:

state planning, urban development, land and property complex, land use, land use and protection, spatial planning.

Земельные отношения в России на протяжении последних десятков лет являются предметом острых дискуссий, а широкий спектр проблем, связанных с земельно-имущественными отношениями, рассматривается с разных точек зрения: экономической, политической, юридической и др. Результаты земельной реформы в нашей стране обсуждаются во всем мире, им также посвящены труды американских ученых [1].

Особенно актуальными являются закрепление прав юридических и физических лиц владения землей, развитие инфраструктуры земельного рынка. При этом совершенствуются механизмы обеспечения охраны и защиты земельных ресурсов, создаются предпосылки повышения качества жизни населения.

В современном городе происходят неизбежные изменения в сложившейся планировочной структуре. Для эфффективного управления использованием земельных ресурсов города разрабатываются документы как долгосрочного планирования, так и краткосрочного: генеральные планы, проекты планировки территорий и т. д. Ведется точечная застройка, при этом возникает дефицит объектов социальной инфраструктуры. Незаменимость земли создает в городском землепользовании объективную необходимость повышения его интенсивности и продуктивности. Экономическое развитие территории города становится основным приоритетом управления земельными ресурсами. Количественным ориентиром для определения выкупной цены земли может выступать кадастровая стоимость земельных участков по первоначальному виду применения, например сельскохозяйственному.

Особые требования к земельным участкам предъявляют инвесторы: у них имеются различия в предпочтениях относительно видов инфраструктур. Для производственных целей инвестора необходимым набором транспортной инфраструктуры выступают наличие автомобильной и железной дорог, грузового порта, аэропорта; инженерной - водоснабжения, канализационной сети, электроснабжения и газификации участка; телекоммуникационной - телефонии, Интернета.

Социальная инфраструктура хотя и обеспечивает условия для нормального развития производственного процесса, но слабо влияет на предпочтения отдельного инвестора. В случае реализации земельного участка или его использования, например, в качестве базы проектов жилой застройки указанные параметры должны быть скорректированы.

Современные условия развития регионов и муниципальных образований характеризуются высокой динамикой фракторов внешней среды. Их динамичность во многом зависит от процессов, 
происходящих в экономике: ее структурного изменения, глобализации, региональной экономической интеграции, развития предпринимательской среды. Все это влияет на усиление взаимосвязей между отдельными процессами и экономическими субъектами. Несмотря на разнообразие и использование разных современных методов прогнозирования, с достаточной точностью предугадать трансфрормацию фракторов внешней среды не представляется возможным, поскольку при построении прогностической модели нельзя учесть все существующие параметры и степень их воздействия на прогнозируемую ситуацию.

Для улучшения социально-экономического развития региона необходимо взаимодействие разных секторов, которое обеспечивается следующими видами поддержки непосредственно внутри них:

- со стороны государственного сектора - финансирование целевых программ, предоставление субсидий населению, инвестирование в инфраструктуру, сопровождение проекта и др.;

- со стороны социального сектора - реализация политики в отношении улучшения качества жизни населения, развитие ипотечного жилищного кредитования, совершенствование мер социальной поддержки и др.;

- со стороны финансового сектора - разработка ипотечных программ для повышения спроса на земельные участки [2].

Процесс вовлечения в активный оборот свободных земельных участков может быть многообразным. Однако наилучшим как для юридического лица, так и для физического является подход, основанный на предпочтениях и возможностях частных лиц и объективной оценке социально-экономической ситуации в регионе, области, муниципальном образовании.

Механизм объединения усилий секторов экономики позволит решить вопросы обеспечения качества земельных участков, предлагаемых инвесторам для дальнейшего развития. Вследствие реализации указанных задач ускоряется вовлечение территорий в хозяйственный оборот и повышается насыщенность процессов функционирования рынка земли.

В Российской Федерации системе государственного планирования использования и охраны земель относительно соответствует одно из его ответвлений - территориальное планирование, фактически отвечающее за градостроительную деятельность [3]. В системе землеустроительной и градостроительной документации присутствуют акты трех уровней: РФ, субъекта РФ, муниципального образования [4]. На каждом уровне территориального планирования формулируются цели и задачи, которые должны соответствовать общей системе целеполагания государственного планирования.

Следует также учитывать риски асимметрии информации, полученной в результате мониторинга, ее искажения, применения некорректных методов ее обработки и интерпретации результатов, которые отрицательно влияют на качество системы государственного информационного обеспечения. По сути документы территориального планирования служат основой создания комфортной среды. Качество подготовленных актов, их доработка находятся в прямой зависимости от степени заинтересованности и участия всех ведомств и подразделений, занимающихся этой работой.

Уникальность любой схемы территориального планирования состоит в том, что ее нормы разрабатываются в соответствии со стратегией развития территории, и проекты развития субъектов экономики регионального и муниципального масштаба должны быть скоординированы. Трудность состоит в том, что сложно предугадать поведение индивидуумов (собственников, инвесторов и т. д.). Ко всему прочему здесь возникают и синергетические эффекты. Любая территория является своеобразной площадкой хозяйствования и взаимодействия большого числа субъектов деятельности разных характера и масштаба, и потому существует необходимость понимания как мотивов самих взаимодействий, так и их механизмов.

Схемы территориального планирования будут действенными только при условии, если станут частью стратегии социально-экономического развития страны, в основе которой лежат освоение и организация российского пространства, если превратятся в один из реальных инструментов управления комплексным развитием территорий. Только в этом случае они будут способствовать достижению сбалансированности пространственного прогресса страны [5].

Основным правовым документом реализации территориального планирования является Градостроительный кодекс РФ, который обязывает исполнительную власть всех уровней иметь утвержденную документацию. Помимо данного акта необходимо учитывать требования других федеральных законов, что также осложняет работу.

Территориальное планирование необходимо для обеспечения устойчивого развития территорий. Но, как показал анализ схем планирования регионального и муниципального уровней, в них слабо представлены предложения по использованию и охране сельскохозяйственных земель. Если качество среды проживания, охрана земель сельхозназначения станут приоритетами государственного стратегического планирования, в рамках документов территориального планирования будут разрабатываться и предложения по улучшению перечисленных параметров. 
При территориальном планировании наблюдается еще ряд проблем. В первую очередь это отсутствие актуальной документации в данной области - генерального плана или схемы планирования, которая определяет стратегическое направление развития территории. В связи со спадом в экономике слабо развиваются градостроительная отрасль и финансирование соответствующей документации, а существовавшие до этого проекты и схемы устарели. Потому необходимость территориального планирования состоит еще и в том, что следует учитывать новые тенденции и концепции градостроительства. Кроме того, фрактически отсутствуют инструменты согласованного использования территориальных природно-экологических ресурсов, что приводит к ухудшению качества среды жизнедеятельности.

Другими проблемами являются недостаточная квалификация экспертов, отсутствие общероссийских нормативов по разработке правил. Часто при подготовке документов территориального планирования специалисты сталкиваются с разночтением многих исходных актов. Это происходит из-за пробела в действующем законодательстве, касающегося требований к последовательности создания и утверждения документов.

Следующий отрицательный момент - слабая взаимосвязь позиций отдельных ведомств муниципальной администрации. Из-за давления со стороны органов власти нередко принимаются решения, основанные на индивидуальном мнении, а это ведет к финансовым потерям и градостроительным ошибкам, которые позже нельзя откорректировать. Цена результатов некомпетентности в данной сфере очень высока, их последствиями становятся многочисленные экономические потери и чрезвычайные ситуации.

Таким образом, в наше время недостаточно эффрективно используется потенциал документов территориального планирования. Применяя их, можно существенно влиять на качество жизни населения, уменьшать дисбаланс территорий, совершенствовать систему расселения.

\section{Ссылки:}

1. Wegren S.K. Land Reform in Russia: Institutional Design and Behavioral Responses. New Haven, 2009. 340 p.

2. Арташина И.А., Жулькова Ю.Н. Анализ взаимодействия и повышение эффективности основных секторов экономики в целях девелопмента земельных участков // Экономический анализ: теория и практика. 2014. № 5 (356). С. 39-49.

3. Градостроительный кодекс Российской Федерации [Электронный ресурс] : федер. закон от 29 дек. 2004 г. № 190 : в ред. от 7 марта 2017 г. Доступ из справ.-правовой системы «КонсультантПлюс».

4. Земельный кодекс Российской Федерации [Электронный ресурс] : федер. закон от 25 окт. 2001 г. № 136-Ф3 : в ред. от 3 марта 2016 г. Доступ из справ.-правовой системы «КонсультантПлюс».

5. Никифоров Л., Кузнецова Т. Схемы территориального планирования в управлении комплексным развитием территорий // Федерализм. 2009. № 2 (54). С. 83-93.

\section{References}

Artashina, IA \& Zhulkova, YuN 2014, 'The analysis of interaction and efficiency improvement of the main economic sectors for the development of the land plots', Ekonomicheskiy analiz: teoriya i praktika, no. 5 (356), pp. 39-49, (in Russian).

Nikiforov, L \& Kuznetsova, T 2009, 'Schemes of territorial planning in managing the integrated territorial development', Federalizm, no. 2 (54), pp. 83-93, (in Russian).

Wegren, SK 2009, Land Reform in Russia: Institutional Design and Behavioral Responses, New Haven, 340 p., https://doi.org/10.12987/yale/9780300150971.001.0001. 